\title{
Differential Combinatorial Coding of Pheromones in Two Olfactory Subsystems of the Honey Bee Brain
}

\author{
Julie Carcaud, ${ }^{1,2,3}$ Martin Giurfa, ${ }^{2,3}$ and $\odot$ Jean-Christophe Sandoz ${ }^{1}$ \\ ${ }^{1}$ Evolution, Genomes, Behavior and Ecology Lab, CNRS, Université Paris-Sud, IRD (UMR 9191), F-91198 Gif-sur-Yvette, France, ${ }^{2}$ Research Center on \\ Animal Cognition, Université de Toulouse, F-31062 Toulouse Cedex 9, France, and ${ }^{3}$ Research Center on Animal Cognition, Centre National de la Recherche \\ Scientifique, F-31062 Toulouse Cedex 9, France
}

\begin{abstract}
Neural coding of pheromones has been intensively studied in insects with a particular focus on sex pheromones. These studies favored the view that pheromone compounds are processed within specific antennal lobe glomeruli following a specialized labeled-line system. However, pheromones play crucial roles in an insect's life beyond sexual attraction, and some species use many different pheromones making such a labeled-line organization unrealistic. A combinatorial coding scheme, in which each component activates a set of broadly tuned units, appears more adapted in this case. However, this idea has not been tested thoroughly. We focused here on the honey bee Apis mellifera, a social insect that relies on a wide range of pheromones to ensure colony cohesion. Interestingly, the honey bee olfactory system harbors two central parallel pathways, whose functions remain largely unknown. Using optophysiological recordings of projection neurons, we compared the responses of these two pathways to 27 known honey bee pheromonal compounds emitted by the brood, the workers, and the queen. We show that while queen mandibular pheromone is processed byl-ALT (lateral antennal lobe tract) neurons and brood pheromone is mainly processed by m-ALT (median antennal lobe tract) neurons, worker pheromones induce redundant activity in both pathways. Moreover, all tested pheromonal compounds induce combinatorial activity from several AL glomeruli. These findings support the combinatorial coding scheme and suggest that higher-order brain centers reading out these combinatorial activity patterns may eventually classify olfactory signals according to their biological meaning.
\end{abstract}

Key words: insect; olfaction; optical imaging; parallel processing; pheromone

\section{Introduction}

Pheromones are used in many behavioral contexts, from reproduction to territoriality, aggression, kin recognition, and food and nest marking (Wyatt, 2003). Neural coding and processing of pheromone information have been studied intensively in insects, strongly focusing on sex pheromones. These studies showed the existence of highly specific olfactory receptor neurons (ORNs) (Christensen and Hildebrand, 2002; Kurtovic et al., 2007) and of brain structures dedicated to pheromone processing, such as the macroglomerular complex of male moths (Christensen and White, 2000; Vickers et al., 2001). These observations supported a labeled-line organization of pheromone processing. However, such an organization is costly in terms of necessary neural units and may only be a particular case for sex pheromones composed of very few components. Consequently, such a coding scheme

\footnotetext{
Received Feb. 20, 2014; revised Dec. 3, 2014; accepted Jan. 11, 2015.

Author contributions: J.C., M.G., and J.-C.S. designed research; J.C. performed research; J.C. and J.-C.S. analyzed data; J.C., M.G., and J.-C.S. wrote the paper.

This work was supported by ANR Project EVOLBEE, ANR-2010-BLAN-1712-01 to J.-C.S., the French Research Ministry to J.C., Institut Universitaire de France to M.G., Centre National de la Recherche Scientifique, and University Paul Sabatier. We thank Maud Combe for developing the custom programs used for data analysis.

The authors declare no competing financial interests.

Correspondence should be addressed to Dr. Jean-Christophe Sandoz, Evolution, Genomes, Behavior and Ecology Lab, CNRS, Université Paris-Sud, IRD (UMR 9191), 1 avenue de la Terrasse, 91198 Gif-sur-Yvette, France. E-mail: sandoz@egce.cnrs-gif.fr.

DOI:10.1523/JNEUROSCI.0734-14.2015

Copyright $\odot 2015$ the authors $\quad 0270-6474 / 15 / 354157-11 \$ 15.00 / 0$
}

may not be adapted for species that use a wide range of different pheromones (often including many different components), such as social insects. In their case, a combinatorial coding scheme, in which each compound activates simultaneously a set of broadly tuned ORNs, appears more realistic (Joerges et al., 1997; Galizia et al., 1999; Zube et al., 2008). Pheromone identity would then reside in a particular combination of activated units, rather than within particular dedicated units. Until now, however, this theoretical view has not been tested systematically in any insect species.

The honey bee Apis mellifera constitutes an advantageous model for addressing this question. Being social insects, bees rely on a wide range of pheromones to ensure cohesion within the colony (Free, 1987). These multicomponent pheromones are emitted by the queen, the workers, and the brood (Free, 1987; Slessor et al., 2005). Despite extensive knowledge on the identity and the behavioral effects of these pheromones, little is known about their coding in the bee brain (Galizia and Menzel, 2001; Sandoz et al., 2007). The bee olfactory circuit is organized in two parallel olfactory subsystems (Galizia and Rössler, 2010): following detection by ORNs and subsequent primary processing in the antennal lobe $(\mathrm{AL})$, olfactory information is conveyed by two main neural tracts of projection neurons (PNs) to higher-order centers: the mushroom bodies (MB) and the lateral horn ( $\mathrm{LH})$ (see Fig. 1A) (Abel et al., 2001; Kirschner et al., 2006). These tracts are termed lateral and medial antennal lobe tracts (1-ALT and 
$\mathrm{m}$-ALT, respectively). Despite intensive study, no clear difference was discovered as their responses to general odorants are mostly redundant (Müller et al., 2002; Krofczik et al., 2009; Carcaud et al., 2012; Nawrot, 2012; Brill et al., 2013).

Here we asked whether pheromones are differentially represented in these two subsystems and whether they are processed according to a combinatorial coding scheme. We visualized, for the first time, the dendritic responses of $\mathrm{m}$-ALT neurons in the $\mathrm{AL}$ and compared pheromone processing in m-ALT and l-ALT neurons. We show that queen and brood pheromones are differentially encoded in the two olfactory subsystems, whereas alarm and aggregation pheromones induce redundant activity. All tested pheromone compounds are processed according to a combinatorial pattern at the PN level.

\section{Materials and Methods}

Animals

Free-flying honey bee foragers (female A. mellifera) were collected at the entrance of an outdoor hive and cooled on ice until they ceased moving. They were then fixed in recording chambers with low temperature melting wax. Each animal was used to record either from the l-ALT subsystem or from the m-ALT subsystem, as visualizing each subsystem requires a different preparation. For visualizing glomeruli belonging to the l-ALT subsystem, the standard preparation was used (Joerges et al., 1997; Sachse and Galizia, 2002; Yamagata et al., 2009). The head capsule between the compound eyes was opened, and then salivary glands and trachea sacks were removed carefully to reveal the two antennal lobes (ALs). For visualizing glomeruli innervated by the m-ALT, a new preparation was recently developed (Carcaud et al., 2012). Honey bees were fixed on their back on a plastic chamber, and the antennae were inserted into a small slit to allow odor presentations from below the chamber. The cuticle, the tentorial arms, glands, and trachea were carefully removed to expose the brain. From this view, the subesophageal ganglion mostly covers the ALs, so it was in part removed to allow recordings of the AL. The brain was immersed in saline solution (in $\mathrm{mm}$ as follows: $130 \mathrm{NaCl}$, $6 \mathrm{KCl}, 4 \mathrm{MgCl}_{2}, 5 \mathrm{CaCl}_{2}, 160$ sucrose, 25 glucose, 10 HEPES, pH 6.7, 500 mOsmol; all chemicals from Sigma-Aldrich). Our previous recordings with this novel preparation used a bath applied calcium dye, which emphasizes activity from ORNs (Carcaud et al., 2012). Here, for the first time, we imaged PNs of the lateral or of the medial tract selectively. Each type of PN was thus stained using the calcium indicator Fura-2 dextran (potassium salt, $10,000 \mathrm{kDa}$, in $2 \% \mathrm{BSA}$; Invitrogen) mixed with tetramethylrhodamine dextran (10,000 kDa; Invitrogen), using a glass electrode coated with crystals of the dye (Sachse and Galizia, 2002; Yamagata et al., 2009). When staining l-ALT neurons, injection aimed for their axonal path, between the $\alpha$ lobe and the border of the optic lobe, rostrally from the LH (see Fig. 1A, "inj1") (Sachse and Galizia, 2002). When staining m-ALT neurons, injections were also aimed for their axonal path, on the medial part of the protocerebrum, rostrally from the AL (see Fig. 1A, "inj2"). The dyes migrated retrogradely to the AL, filling either glomeruli innervated by m-ALT PNs or glomeruli innervated by l-ALT PNs. After staining, the bee was left in a moist and dark place for $3 \mathrm{~h}$. A neuroanatomical step (see below) ensured that neuronal staining of either the 1-ALT or the m-ALT neurons was efficient and homogeneous.

\section{Optical recordings}

Calcium imaging measurements were performed in standard conditions (Deisig et al., 2010; Mota et al., 2011), using a T.I.L.L. Photonics imaging setup. Bees stained with Fura-2 dextran were placed under an epifluorescent microscope (Olympus BX-51WI) with a $10 \times$ water-immersion objective (Olympus, UMPlanFL; NA 0.3). Recordings were taken using a $640 \times 480$ pixel 12 -bit monochrome CCD-camera (T.I.L.L. Imago) cooled to $-12^{\circ} \mathrm{C}$. Fura- 2 was alternatively excited with 340 and $380 \mathrm{~nm}$ monochromatic light (T.I.L.L. Polychrom IV). Each measurement consisted of 100 double frames, at a rate of $5 \mathrm{~Hz}$ (interval between double frames: $200 \mathrm{~ms}$ ), with $4 \times 4$ binning on chip (pixel image size corresponded to $4.8 \mu \mathrm{m} \times 4.8 \mu \mathrm{m})$. The filter set on the microscope was
Table 1. Summary of pheromonal components used in this study

\begin{tabular}{|c|c|c|c|}
\hline Pheromone type & Compound & Abbreviation & $\begin{array}{l}\text { Vapor pressure } \\
(\mathrm{mmHg})\end{array}$ \\
\hline \multirow{5}{*}{$\begin{array}{l}\text { Queen mandibular } \\
\text { compounds (QM) }\end{array}$} & Homovanillyl alcohol & HVA & $2.04 \times 10^{-5}$ \\
\hline & Methyl 4-hydroxybenzoate & HOB & $2.37 \times 10^{-4}$ \\
\hline & 9-0xo-(E)-2-decenoic acid & 9-0DA & $1.77 \times 10^{-6}$ \\
\hline & $\begin{array}{l}\text { 9-Hydroxy-(E)-2-decenoic } \\
\text { acid }\end{array}$ & 9-HDA & $2.87 \times 10^{-6}$ \\
\hline & $\begin{array}{l}\text { 10-Hydroxy-(E)-2-decenoic } \\
\text { acid }\end{array}$ & $10-\mathrm{HDA}$ & $6.28 \times 10^{-6}$ \\
\hline \multirow{3}{*}{$\begin{array}{l}\text { Queen nonmandibular } \\
\text { compounds (QnM) }\end{array}$} & Coniferyl alcohol & - & $8.80 \times 10^{-6}$ \\
\hline & 1-Hexadecanol & $1-160 \mid$ & $6.00 \times 10^{-6}$ \\
\hline & Linolenic acid & - & $5.40 \times 10^{-7}$ \\
\hline \multirow{6}{*}{$\begin{array}{l}\text { Brood compounds } \\
\quad \text { (brood) }\end{array}$} & Methyl linoleate & - & $3.67 \times 10^{-6}$ \\
\hline & Methyl linolenate & m. linolenate & $5.07 \times 10^{-6}$ \\
\hline & Ethyl oleate & - & $6.07 \times 10^{-5}$ \\
\hline & Methyl oleate & - & $6.29 \times 10^{-6}$ \\
\hline & Ethyl palmitate & - & $2.34 \times 10^{-5}$ \\
\hline & Methyl palmitate & - & $4.70 \times 10^{-5}$ \\
\hline \multirow{9}{*}{$\begin{array}{l}\text { Alarm compounds } \\
\quad \text { (alarm) }\end{array}$} & Isopentyl acetate & IPA & 5.60 \\
\hline & 2-Heptanone & 2-7one & 3.86 \\
\hline & 1-Butanol & $1-40 l$ & 6.70 \\
\hline & 1-Hexanol & $1-601$ & 0.93 \\
\hline & 1-0ctanol & $1-801$ & $7.94 \times 10^{-2}$ \\
\hline & 2-Nonanol & $2-901$ & $6.76 \times 10^{-2}$ \\
\hline & 0ctyl acetate & - & 0.22 \\
\hline & Benzyl acetate & - & 0.17 \\
\hline & Hexyl acetate & - & 1.32 \\
\hline \multirow{4}{*}{$\begin{array}{l}\text { Aggregation } \\
\text { compounds } \\
\text { (aggregation) }\end{array}$} & Geranic acid & - & $3.27 \times 10^{-3}$ \\
\hline & Farnesol & - & $2.52 \times 10^{-4}$ \\
\hline & Citral & - & $9.13 \times 10^{-2}$ \\
\hline & Geraniol & - & $3.00 \times 10^{-2}$ \\
\hline
\end{tabular}

composed of a $490 \mathrm{~nm}$ dichroic filter and a bandpass (50 nm) $525 \mathrm{~nm}$ emission filter. Integration time was $10-20 \mathrm{~ms}$ at $380 \mathrm{~nm}$ excitation and $40-80 \mathrm{~ms}$ at $340 \mathrm{~nm}$ excitation. Olfactory stimulation started at the 15 th frame until the 20th frame, for $1 \mathrm{~s}$.

\section{Olfactory stimuli}

The queen communicates her presence and influences the colony by releasing a queen mandibular pheromone (QMP) together with compounds from other glandular origin (Slessor et al., 2005; Sandoz et al., 2007). Workers produce several types of pheromones acting in different behavioral contexts, such as colony defense (Boch et al., 1962; Shearer and Boch, 1965; Free, 1987) and aggregation among nestmates (Pickett et al., 1980; Free, 1987). Finally, the brood communicates with workers using a pheromone composed of fatty-acid esters (Le Conte et al., 1990, 2001). In this study, we tested the major compounds of these four main pheromone types detected by worker bees (Table 1) as follows:

1. Queen-emitted pheromone compounds. We tested two groups of compounds of the queen pheromone, from different glandular sources: we tested five mandibular compounds (henceforth "queen mandibular compounds"): 9-oxo-(E)-2-decenoic acid (9-ODA), (R)- and (S)-9hydroxy-(E)-2-decenoic acid (9-HDA), methyl 4-hydroxybenzoate (HOB), and 4-hydroxy-3-methoxyphenylethanol [i.e. homovanillyl alcohol (HVA)] and (R)- and (S)-10-hydroxy-(E)-2-decenoic acid (10HDA). A mixture of the first four compounds presented in proportions corresponding to a mated queen, called QMP as in its original description (Slessor et al., 1988), was also tested. We also tested three queen nonmandibular compounds, which form the queen retinue pheromone together with the QMP mixture: coniferyl alcohol, 1-hexadecanol, and linolenic acid (Keeling et al., 2003).

2. Brood-emitted pheromone compounds (henceforth "brood compounds"). Six components of the brood pheromone were tested: methyl linoleate, methyl linolenate, ethyl oleate, ethyl palmitate, methyl oleate, and methyl palmitate. 

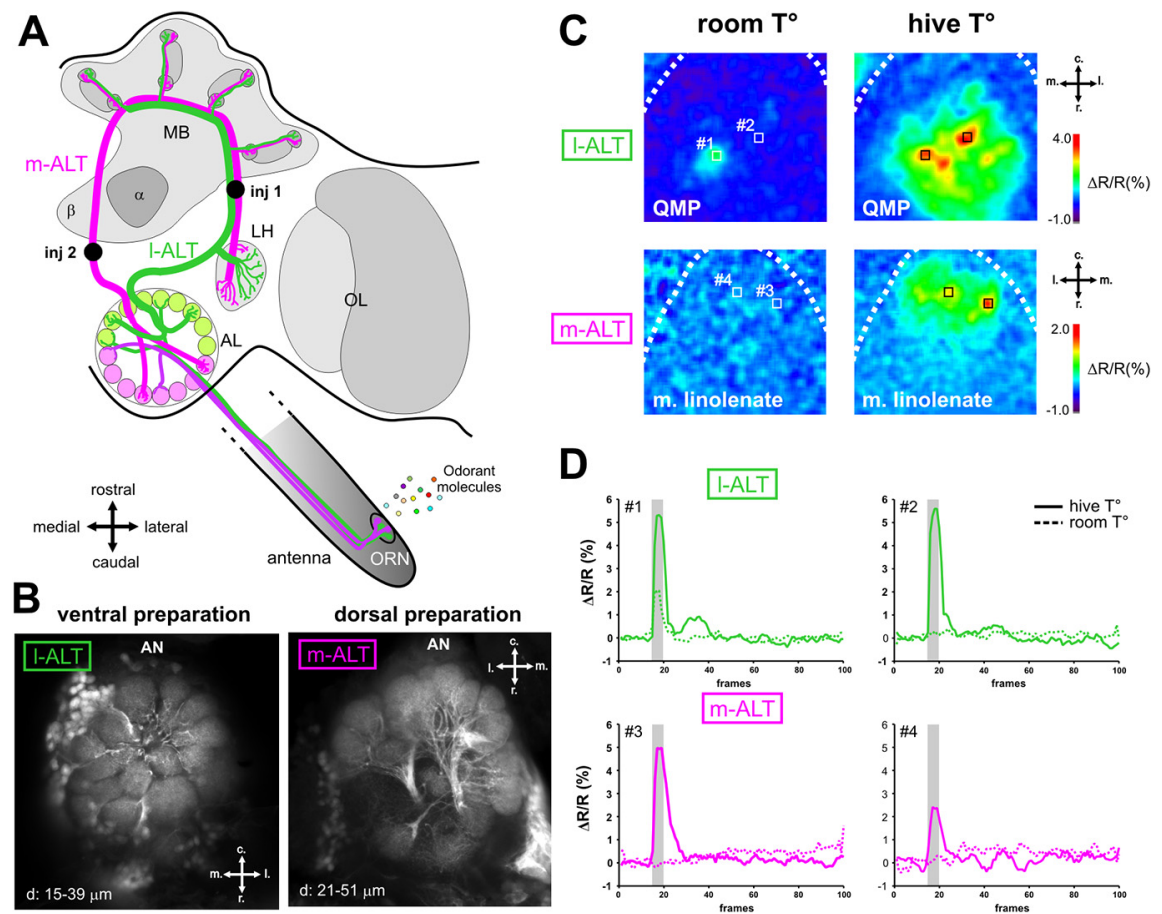

Figure 1. Calcium signals from m-ALT and I-ALT PNs to pheromonal odorants. A, Dual olfactory pathway of the honey bee brain (adapted from Carcaud et al., 2012). Odorant molecules are detected by ORNs on the antenna, forming the antennal nerve (AN) and project to the AL. Then, PNs convey information to the MB and the LH via two main tracts: the m-ALT (magenta) and the I-ALT (green). Injection locations are shown as black dots (inj1 and inj2). 0L, Optical lobe. B, Retrograde staining of I-ALT PNs (left) and m-ALT PNs (right) innervating, respectively, ventral and dorsal AL glomeruli.Z-projection of optical slices at the indicated depths. C, Odor-induced calcium signals in the AL at room temperature $\left(\sim 25^{\circ} \mathrm{C}\right.$, left $)$ or at hive temperature $\left(35^{\circ} \mathrm{C}\right.$, right), for I-ALT PNs to QMP (top) and for m-ALT PNs to methyl linolenate (bottom). Relative fluorescence changes $(\Delta R / R \%)$ are presented in a false-color code, from dark blue to red. $\boldsymbol{D}$, Time course of $\Delta \mathrm{R} / \mathrm{R} \%$ during a $20 \mathrm{~s} 5 \mathrm{~Hz}$ recording for I-ALT (top) and $\mathrm{m}$-ALT PNs (bottom). The signals from different glomeruli (1-4) located as indicated in C are shown for room $\mathrm{T}^{\circ}$ (dashed lines) and hive $\mathrm{T}^{\circ}$ (solid lines).

3. Worker-emitted pheromones used in a defense context (henceforth "alarm compounds"). These compounds included components of the sting pheromone, which are used in an alarm context: isopentyl acetate, 1-octanol, 2-nonanol, 1-butanol, benzyl acetate, octyl acetate, and hexyl acetate. We also placed in this group the worker-emitted mandibular compound 2-heptanone, also used in a defense context for marking enemies. This component was also suggested as a potential marking pheromone for depleted foraging sites (Giurfa and Núñez, 1992).

4. Worker-emitted pheromones emitted in an attraction/aggregation context (henceforth "aggregation compounds"). Four components of the aggregation pheromone produced by the Nasanov gland were tested: geraniol, (E,E)-farnesol, and (E)- and (Z)-citral and geranic acid.

Because of the high number of compounds in our odor panel, the experiments were carried out on four groups of animals. The first experiment studied the representation of queen and brood pheromone compounds in two groups of honey bees, imaging either 1-ALT neurons or $\mathrm{m}$-ALT neurons. These compounds were presented at a concentration of $50 \mu \mathrm{g} / \mu \mathrm{l}$ in isopropanol. In this experiment, 5 odorants with a previously known glomerular patterns were also presented for reference (1nonanol, 2-heptanone, 2-octanol, hexanal, and isopentyl acetate, presented pure). The second experiment studied the representation of alarm and aggregation compounds also in two groups of honey bees, imaging either l-ALT neurons or m-ALT neurons. Pure compounds were used for stimulation.

Several queen mandibular compounds (9-ODA, 9-HDA, 10-HAD, and the QMP mixture) were obtained from Pherotech in isopropanol. All other compounds were obtained from Sigma-Aldrich. All stimuli consisted of $5 \mu \mathrm{l}$ of diluted or pure odorant, as detailed above, placed on a filter paper $\left(1 \mathrm{~cm}^{2}\right)$ inserted into a Pasteur pipette. As control stimulus, a pipette containing the solvent (isopropanol) in the first experiment, and a clean piece of filter paper in both experiments was used. The order of odor presentations was randomized between bees, and each bee was subjected to 2 or 3 presentations of each odorant.

\section{Olfactory stimulation}

Under the microscope, a constant clean airflow of $50 \mathrm{ml} / \mathrm{s}$ was directed through a $1-\mathrm{cm}$ diameter glass tube to the bee's antennae, at a distance of $2 \mathrm{~cm}$. During odor stimulation, a secondary airflow of $2.5 \mathrm{ml} / \mathrm{s}$ was diverted from the main airflow and passed through an interchangeable glass pipette containing a $1 \mathrm{~cm}^{2}$ filter paper soaked with odor substance (see above). Stimulations were controlled by the computer of the imaging system.

In Experiment 1, because the vapor pressure of queen and brood compounds is low compared with those of odorants usually presented in imaging experiments (floral compounds), volatility was increased by increasing the stimulus temperature to $35^{\circ} \mathrm{C}$, which is the normal hive temperature at which these components are used by bees (Winston, 1987). Such a heating procedure has been used with success in previous studies to record neural responses to odorants of low volatility (Brandstaetter and Kleineidam, 2011; Brill et al., 2013). This was done by placing the Pasteur pipettes in an incubator at $\sim 65^{\circ} \mathrm{C}$ between stimulations. The temperature at the air outlet in front of the bee (i.e., after injection of the secondary airflow into the main airflow) was regularly controlled to be $35 \pm 1^{\circ} \mathrm{C}$ with a standard wire thermometer (VC150, Voltcraft). Consequently, the temperature of the stimulation was elevated only during odor stimulation, the insect remaining otherwise at room temperature. To control for any effect of temperature alone, the isopropanol control was also presented at $35^{\circ} \mathrm{C}$. We did not observe responses to temperature alone. In Experiment 2 , odorants were presented at room temperature $\left(25^{\circ} \mathrm{C}\right)$, as they are more volatile, are mostly used outside of the hive, and trigger good calcium imaging signals in normal conditions. The air control was accordingly presented at room temperature.

Anatomical staining. After functional imaging, the brains were dissected and fixed in $4 \%$ formaldehyde in PBS overnight at $4^{\circ} \mathrm{C}$. The next day, the brains were rinsed in PBS, dehydrated in standard ethanol series, and cleared in methyl salicylate (Sigma-Aldrich). Visualization of the stained glomeruli in each AL was performed with a confocal laserscanning microscope (Zeiss LSM 700), using an excitation wavelength of $555 \mathrm{~nm}$. The AL was scanned with a W Plan-Apochromat 20×/1.0 objective (Zeiss).

Orientation. As we never observed any differences between brain hemispheres in this work, left and right ALs were indifferently stained, imaged, and observed under confocal microscopy. For ease of reference, however, all lobes shown in the figures are shown as right ALs, and were flipped if they were left ALs.

\section{Raw data processing}

Analysis of calcium-imaging data was carried out using IDL 6.0 (Research Systems). Each recording to an odor stimulus corresponded to a 4 -dimensional array with the excitation wavelength ( 340 or $380 \mathrm{~nm}$ ), two spatial dimensions ( $x, y$ pixels of the area of interest), and the temporal dimension (100 frames). Three steps were performed to calculate the odor-response values on which data analysis was performed (Galizia and Vetter, 2004). First, the ratio $R=F_{340 \mathrm{~nm}} / F_{380 \mathrm{~nm}}$ of $\mathrm{Ca}^{2+}$ signals from 340 and $380 \mathrm{~nm}$ measurements was calculated at each pixel and time point. Relative ratio changes were calculated as $\Delta R / R=\left(R-R_{0}\right) / R_{0}$, taking as reference background $R_{0}$ the average of five frames just before any olfactory stimulation (frames $10-14$ ). Thus, $\Delta \mathrm{R} / \mathrm{R}$ is close to 0 shortly before 
the odor stimulus and shows throughout a recording the relative variations of the ratio. Second, to reduce the effects of photon and electronic noise, the raw data were filtered in the two spatial and in the temporal dimension using a median filter with a size of 3 pixels. Third, a bleach correction was applied, subtracting a logarithmic curve fitted to the median brightness decay of the entire image frames, excluding the frames during the stimulus until $5 \mathrm{~s}$ after stimulus onset (Galizia and Vetter, 2004). Such a correction stabilizes the baseline of the recordings, without affecting odor-evoked responses. At this time, each recording to an odorant was a 3-dimensional array with $x, y$ pixels and 100 frames. We then calculated odor-response maps, which contained the amplitude of the calcium response for each pixel. Odor-response maps were calculated as the mean of three frames during the stimulus (frames 17-19) minus the mean of 3 frames before odor presentation (frames 12-14). These maps were used in all further calculations as detailed below. For better visualization of activity spots, odor-response maps were subjected to a Gaussian $(7 \times 7)$ and presented in a false-color code of increasing amplitude from dark blue to red in the figures. For data analysis, the Gaussian-filtered maps obtained for the two to three presentations of each odor were averaged within each individual bee.

\section{Data analysis}

To ensure reliable conclusions, we performed two complementary types of analyses, a pixelwise analysis on the whole AL surface (thereby using all visually accessible glomeruli) and a glomerular analysis, which focused on a limited set of activity spots within each AL.

Pixelwise analysis. For each bee, a mask was precisely drawn around the AL to remove from the analysis non-AL regions of the recordings. All pixels of the AL within the mask were used in the calculations, ensuring a comprehensive and unbiased analysis that does not depend on any decision made by the experimenter. For each odorant presentation, the global response intensity was calculated as the average amplitude of the response over all pixels located within the unmasked area (see Figs. $2 B$ and $5 B$ ). We also measured the (dis-)similarity in odor response maps between any two pairs of odorants. For this, we calculated pixelwise Euclidian distances for all odor pairs within each animal, according to the following equation:

$$
d_{i j}=\sqrt{\sum_{k=1}^{p}\left(X_{i k}-X_{j k}\right)^{2}},
$$

with $i$ and $j$ indicating odorants, $p$ the number of pixels in the unmasked area, and $X_{i k}$ the amplitude of the response in pixel $k$ to odor $i$.

To explore the similarity relationships among pheromonal odorants within each neural population (1-ALT and m-ALT), we performed cluster and proximity analyses based on pixelwise Euclidian distances averaged over all animals. Cluster analysis provided a hierarchical clustering of single odors according to their distance in the defined olfactory space, using Ward's classification method. Proximity analysis (also called multidimensional scaling or principal coordinate analysis) is an alternative to principal component analysis that allows determining main dimensions explaining similarity relation- queen mandibular queen non-mandibular

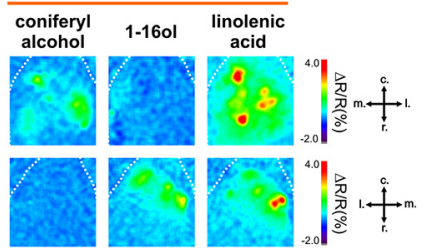

brood
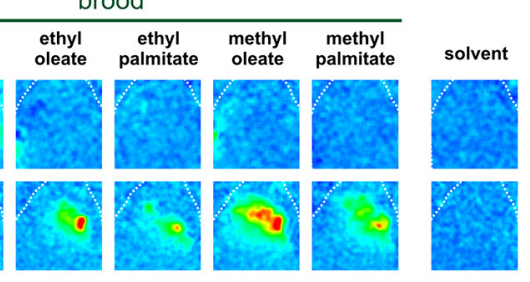

C
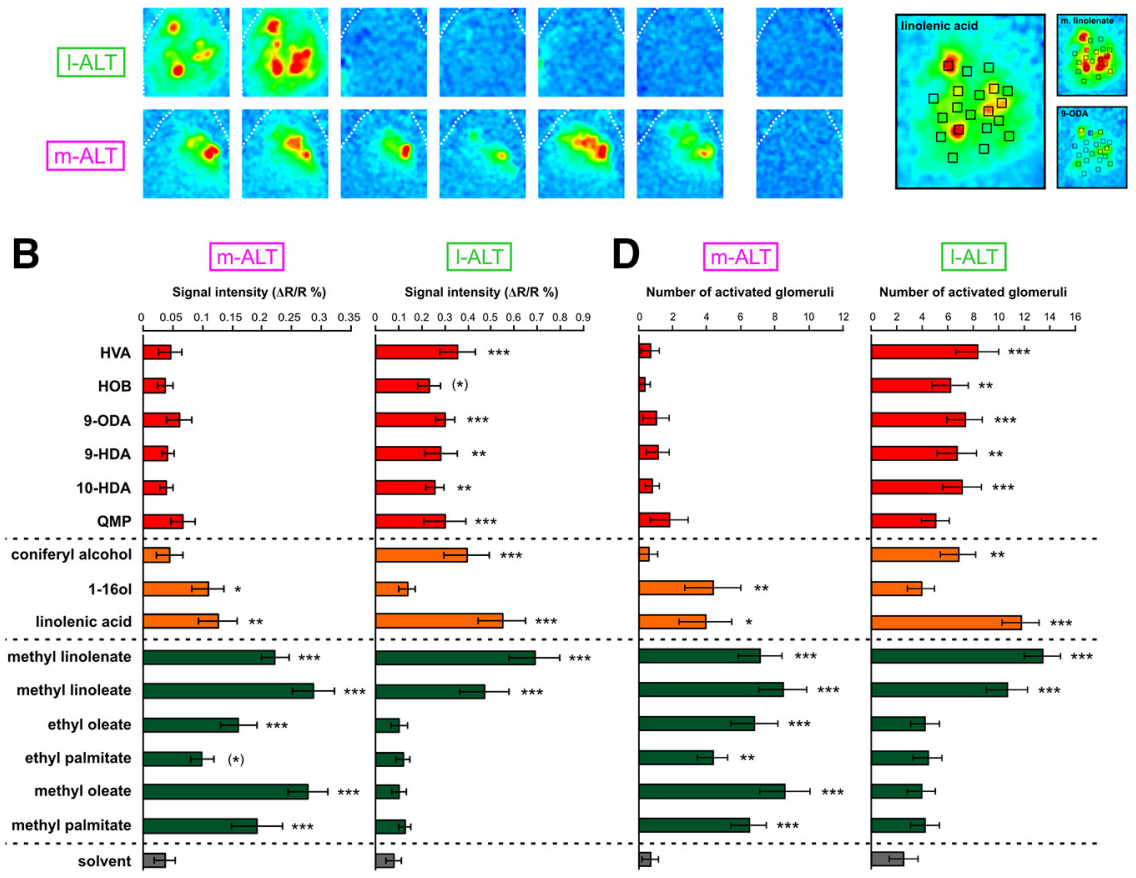

Figure 2. Responses to queen and brood pheromone compounds in I-ALT and m-ALT PNs. A, Odor-induced calcium activity maps obtained from I-ALT (top) and m-ALT neurons (bottom) in two different animals, to 5 queen mandibular compounds and the fuorescence changes $(\Delta R / R \%)$ are presented in a false-color code, from dark blue to red. $\boldsymbol{B}$, Pixelwise analysis. Amplitude of enses $(\Delta \mathrm{R} / \mathrm{R} \%)$ in the antennal lobe for m-ALT $(n=9)$ and I-ALT neurons $(n=10)$ to queen mandibular compounds 9) and I-ALT neurons $(n=10)$. Error bars indicate the SEM across animals. Stars on the right of each bar indicate significant difference compared with solvent (Dunnett's test). ${ }^{*} p<0.05 ;{ }^{* *} p<0.01 ;{ }^{* * *} p<0.001 ;\left({ }^{*}\right) p<0.1$.

ships within a dataset based on the matrix of interodor distances. Both analyses were performed using Statistica 5.5 and confirmed with $\mathrm{R}$ (www.r-project.org).

Glomerular analysis. we also wanted to determine the odor-response spectrum of individual glomerular units. On each imaged AL, the experimenter visually chose a set of 20 glomerular-sized areas of interest, based on the activity maps obtained for the different odorants (see example in Fig. 2C). This set comprised most (if not all) clearly segregated activity spots observed within each AL for any of the odorants. Each area of interest had a size of $5 \times 5$ pixels, well within the size of a glomerulus. The response intensity of each glomerulus was the average of the response of the 25 pixels of the area of interest. Extensive previous data on the glomerular outlay of the honey bee antennal lobe (Kirschner et al., 2006; Hourcade et al., 2009; Galizia et al., 2012) and on the use of this selection method (Dupuy et al., 2010; Carcaud et al., 2012) allow considering each of these areas of interest as a glomerulus. Despite our efforts, m-ALT glomeruli could not be unambiguously identified between different animals. For this reason, we cannot be sure that the exact same set of glomeruli was selected in different individuals, although visual observation suggested a high overlap. Accordingly, responses from activity spots 

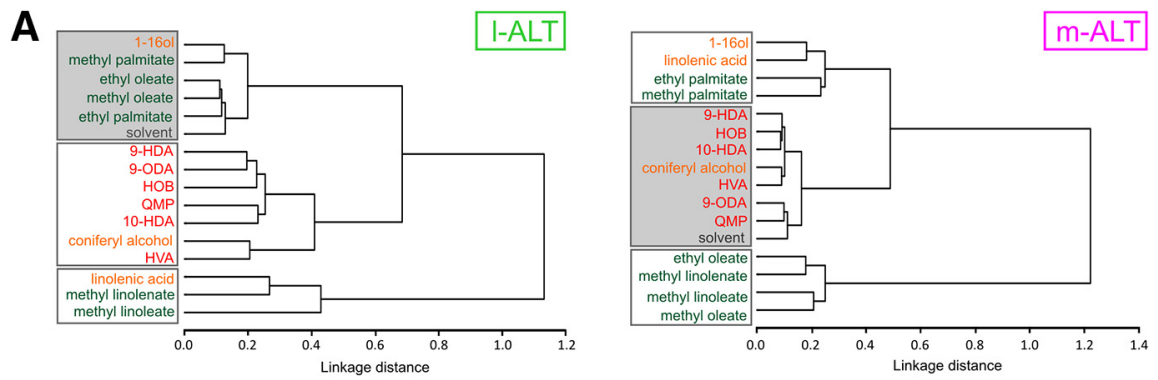

B
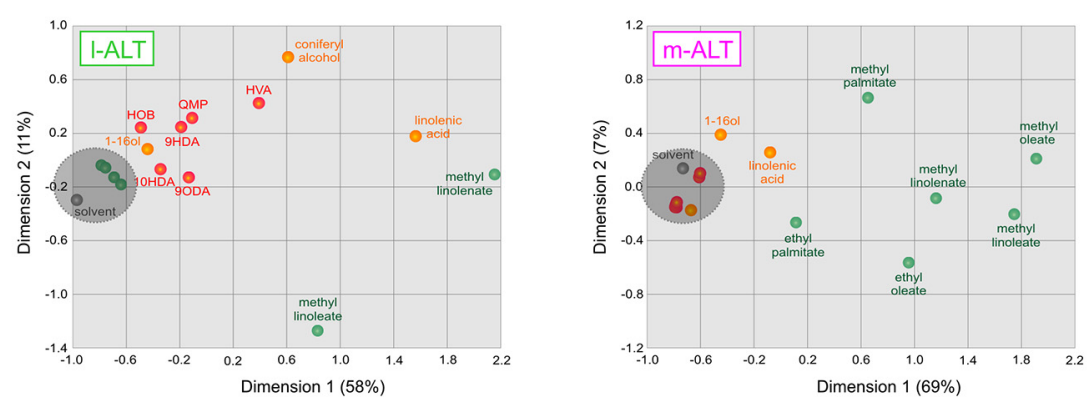

Figure 3. Coding of queen and brood pheromone compounds in both subsystems. These analyses are based on pixelwise Euclidian distances between odor representations after averaging across animals, for l-ALT (left) and m-ALT neurons. $\boldsymbol{A}$, Cluster analysis showing similarity relationships among representations of queen and brood pheromone compounds (Ward's method). Higher linkage distances correspond to more dissimilar odorants. Red represents queen mandibular compounds; orange represents queen nonmandibular compounds; green represents brood pheromone compounds. Gray represents the solvent. Gray background represents noncoding compounds within each neuron type (Fig. 2B). White background represents compounds processed within each subsystem. B, Proximity analysis (multidimensional scaling). The two main dimensions explain $69 \%$ and $76 \%$ of overall variance for I-ALT (left) and m-ALT neurons (right), respectively.

could not be averaged across individuals. Each glomerulus was considered as activated by a given odorant when its response was $>5 \mathrm{SD}$ of the signal before the stimulus (frames 1-13). Within each animal, we then calculated for each tested odorant the number of statistically activated glomeruli and for each glomerulus, the number of activating odorants.

As these calculations include a thresholding step based on noise levels, which may be different in 1-ALT and m-ALT systems, we also used direct measures of representation sparseness. Population sparseness refers to the distribution of responses of a population of neural units to a single stimulus, whereas lifetime sparseness refers to the distribution of responses of a single neural unit across many stimuli (Willmore et al., 2011). These measures have been used for studying representation specificity in the olfactory system of locusts, fruit flies, and bees (Perez-Orive et al., 2002; Bhandawat et al., 2007; Brill et al., 2013). Population sparseness was calculated for each odorant over all recorded glomeruli in all animals, as follows:

$$
P S_{i}=\frac{1}{1-1 / N}\left(1-\frac{\left(\sum_{k=1}^{N} X_{i k} / N\right)^{2}}{\sum_{k=1}^{N} X_{i k}^{2} / N}\right)
$$

with $N$ being the number of glomeruli and $X_{i k}$ the response to odorant $i$ in glomerulus $k . X_{i k}$ was calculated as the average of response amplitude over the 25 pixels of each glomerulus. Population sparseness can be used as a normalized measure of the selectivity of an odor representation. Its values range from 0 (nonselective) to 1 (maximally selective). Population sparseness was calculated for each odor stimulus within each individual bee and then averaged across individuals.

Lifetime sparseness was calculated for each glomerulus over each panel of tested odorants as follows:

$$
L S_{k}=1-\frac{\left(\sum_{i=1}^{n} X_{i k} / n\right)^{2}}{\sum_{i=1}^{n} X_{i k}^{2} / n}
$$

with $n$ being the number of tested odorants and $X_{i k}$ the response to odorant $i$ in glomerulus $k$. Lifetime sparseness can be used as a normalized measure of the narrowness of a glomerulus odor-response spectrum. Its values range from 0 (maximally broad) to 1 (maximally narrow). Following standard practice, any negative value of $X_{i k}$ was set to 0 before computing either population or lifetime sparseness (Bhandawat et al., 2007).

Statistical analysis. Within each neural population (l-ALT and $\mathrm{m}$-ALT), global response intensity to the different pheromone components and number of activated glomeruli were compared using ANOVA for repeated measurements. When significant, Dunnett's test was applied to compare the intensity or the number of activated glomeruli of each pheromone component to a common reference, either the solvent control (queen mandibular, queen nonmandibular, and brood pheromone compounds) or the air control (alarm and aggregation compounds). To evaluate the similarity in the responses of $\mathrm{m}$-ALT and 1-ALT neurons to each set of odorants, global response intensity and number of activated glomeruli values obtained in both subsystems for the different odorants were subjected to Pearson correlation analyses. Population and lifetime sparseness values were compared between neural populations using a Mann-Whitney test. Statistical analyses were performed using Statistica 5.5 and confirmed with R (www. r-project.org).

\section{Results}

In a first experiment, we quantified the responses of 1-ALT PNs (Fig. $1 B ; n=10$ bees) and $\mathrm{m}$-ALT PNs ( $n=9$ bees) to the QMP mixture and 5 queen mandibular compounds, 3 queen nonmandibular compounds, and 6 components of the brood pheromone. In a second experiment, we studied the responses of both PN types (1-ALT: $n=10$ bees, m-ALT: $n=8$ bees) to 9 compounds released by workers in an alarm/defensive context (henceforth, alarm pheromone) and 4 compounds released in an attraction/ aggregation context (henceforth, aggregation pheromone). All compounds are detailed in Table 1.

Previous studies reported that QMP or its components induce only very weak activity in AL glomeruli innervated by l-ALT PNs (Galizia et al., 1999; Sandoz et al., 2007), whereas components of alarm or aggregation pheromones induce clear signals (Galizia et al., 1999; Sandoz et al., 2007; Wang et al., 2008). It was proposed that QMP components may be processed in m-ALT glomeruli, which were inaccessible to calcium imaging. However, our initial recordings of m-ALT PN activity did not substantiate this hypothesis as no activity could be recorded upon stimulation with these compounds. This result can be explained by the low vapor pressures of queen mandibular compounds, which contrast with the higher vapor pressures of alarm- or aggregation-pheromone components (Table 1). In nature, queen and brood pheromones act as communication signals within the warm-regulated atmosphere of the hive (i.e., at $\sim 35^{\circ} \mathrm{C}$ ) (Free, 1987). Thus, testing the response of the bee olfactory system to these substances in a 
realistic environment requires setting the stimulation airstream at hive temperature. By doing so, we were able to record clear calcium responses to queen and brood pheromones in $\mathrm{m}$-ALT or 1-ALT PNs. For instance, although QMP elicited very weak activity in l-ALT PNs at room temperature $\left(25^{\circ} \mathrm{C}\right)$, it induced clear glomerular signals at hive temperature (Fig. $1 C, D$, top). Likewise, although no response could be detected in m-ALT PNs upon stimulation with methyl linolenate at room temperature, clear signals were obtained at hive temperature (Fig. $1 C, D$, bottom). In the rest of the study, all presentations of queen and brood pheromones were performed at hive temperature.

\section{Differential processing of queen and brood pheromones}

The 5 queen mandibular compounds induced clear activity patterns in l-ALT neurons but not in m-ALT neurons (Fig. 2A). Accordingly, in 1-ALT neurons, global response intensity for these compounds was significantly higher than for the solvent (Fig. $2 B$, Dunnett's post hoc tests, $p<0.01$ ), except for methyl $p$-hydroxybenzoate, which was only nearly significant $(p=0.08)$. Responses in m-ALT neurons were all nonsignificant. Conversely, all brood pheromone components induced specific activity patterns in m-ALT neurons (Fig. $2 A)$, with response intensity significantly above solvent (Fig. 2B, Dunnett's post hoc tests, $p<0.001)$, except for ethyl palmi-

tate $(p=0.09)$. In 1-ALT neurons, only 2 brood components, methyl linolenate and methyl linoleate, induced significant responses (Fig. $2 A, B, p<0.001$ ). The three queen nonmandibular components induced distinct activity in both subsystems (Fig. $2 A, B)$. In addition to global response intensity, we also compared the number of activated glomeruli measured for each odorant in both neuron types (Fig. 2C,D; activity $>5 \mathrm{SD}$ of signal before stimulus). Queen mandibular pheromone components induced significant numbers of activated glomeruli in l-ALT neurons, but not in m-ALT neurons. Conversely, all brood pheromone components activated a significant number of glomeruli in $\mathrm{m}$-ALT neurons, but not in l-ALT neurons (Fig. 2C, Dunnett's post hoc tests, $p<0.05$ ). These results clearly show that the processing of queen and brood pheromone components is segregated in the two AL subsystems.

\section{Qualitative coding of queen and brood pheromones}

As shown by the activity maps in Figure $2 A$, the different pheromonal odorants induced different patterns of glomerular activity within each subsystem. We thus analyzed qualitative coding of these pheromones in the two subsystems. We calculated pixelwise Euclidian distances, a measure of dissimilarity, between the activity maps of all stimuli in our dataset ( $n=120$ stimulus pairs) within each animal, and averaged them over all animals of each group. The obtained distance matrices were used in multidimensional analyses. As expected from the previous results, cluster
B

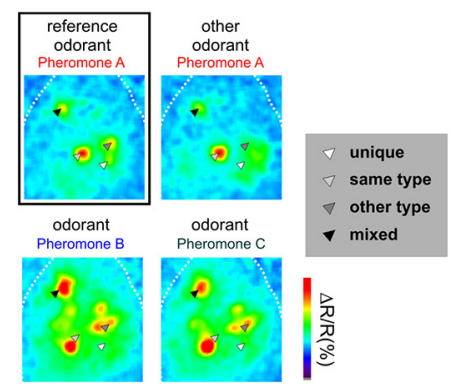

$\%$ cases
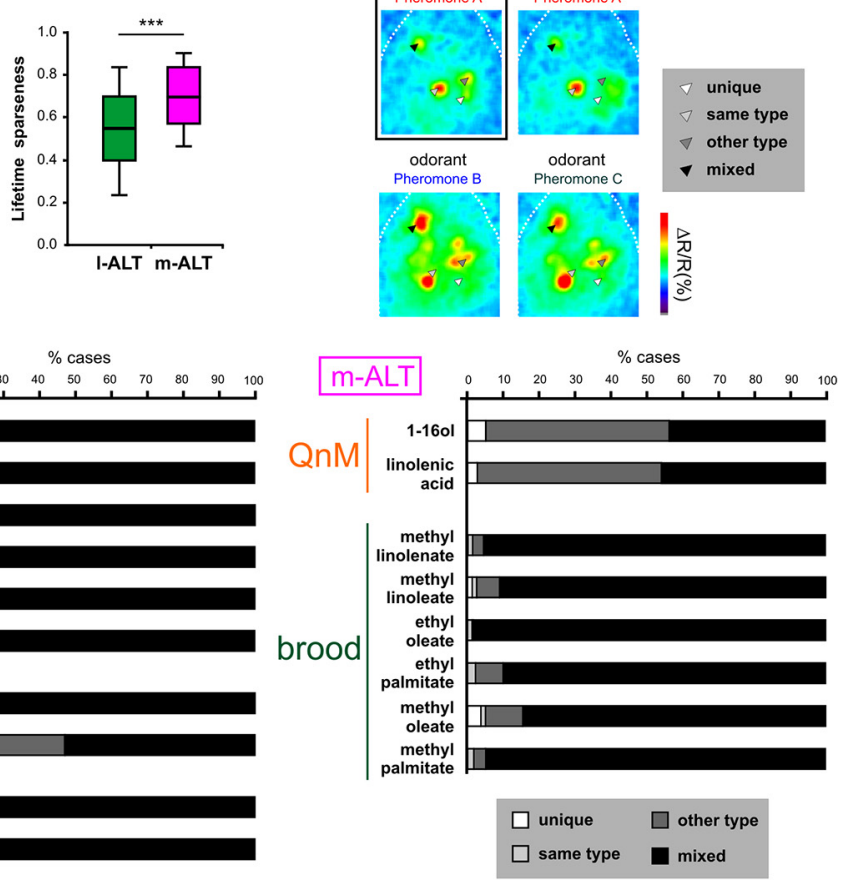

Figure 4. Representation sparseness and glomerular coactivation for queen and brood pheromone. $\boldsymbol{A}$, Population sparseness and lifetime sparseness measured from I-ALT and m-ALT recordings to queen and brood pheromones. Boxes represent the median dhird quartiles. Whiskers represent $10 \%$ and $90 \%$ percentiles. ${ }^{* * *} p<0.001$. B, Glomerular coactivation. Principle for arrow, only activated by the reference odorant), same type glomerulus (light gray arrow, activated by the reference odorant of glomeruli for each pheromone compound and for all the glomeruli they activate: white represents unique; light gray represents same type; dark gray represents other type; black represents mixed.

analyses first segregated substances significantly activating (white boxes) or not (gray boxes) each subsystem (Fig. 3A, Ward's classification). Moreover, within m-ALT or l-ALT neurons, the different sets of activating compounds were segregated based on their pheromone nature (see queen and brood compounds in l-ALT neurons). Likewise, in proximity (multidimensional scaling) analyses (Fig. 3B), the different pheromone types were grouped in different parts of the neural space. In addition, within each pheromone type, the different components occupied different positions (e.g., the homogeneous repartition of brood pheromone components in m-ALT neurons). Thus, queen and brood pheromone components induce differential representations in both subsystems.

Representation sparseness and glomerular responses to queen and brood pheromones

To ask how narrowly tuned pheromone representations are in 1-ALT and m-ALT neurons, we used the glomerular data to calculate standard measures of representation sparseness (i.e., population and lifetime sparseness) (Fig. 4A). These calculations show that pheromone representations are rather moderately sparse, with median values of 0.62 (l-ALT) and 0.75 (m-ALT) for population sparseness (distribution of responses of the population of glomeruli for a single stimulus) and 0.54 (l-ALT) and 0.69 (m-ALT) for lifetime sparseness (distribution of responses of a single glomerulus across many stimuli). In agreement with pre- 

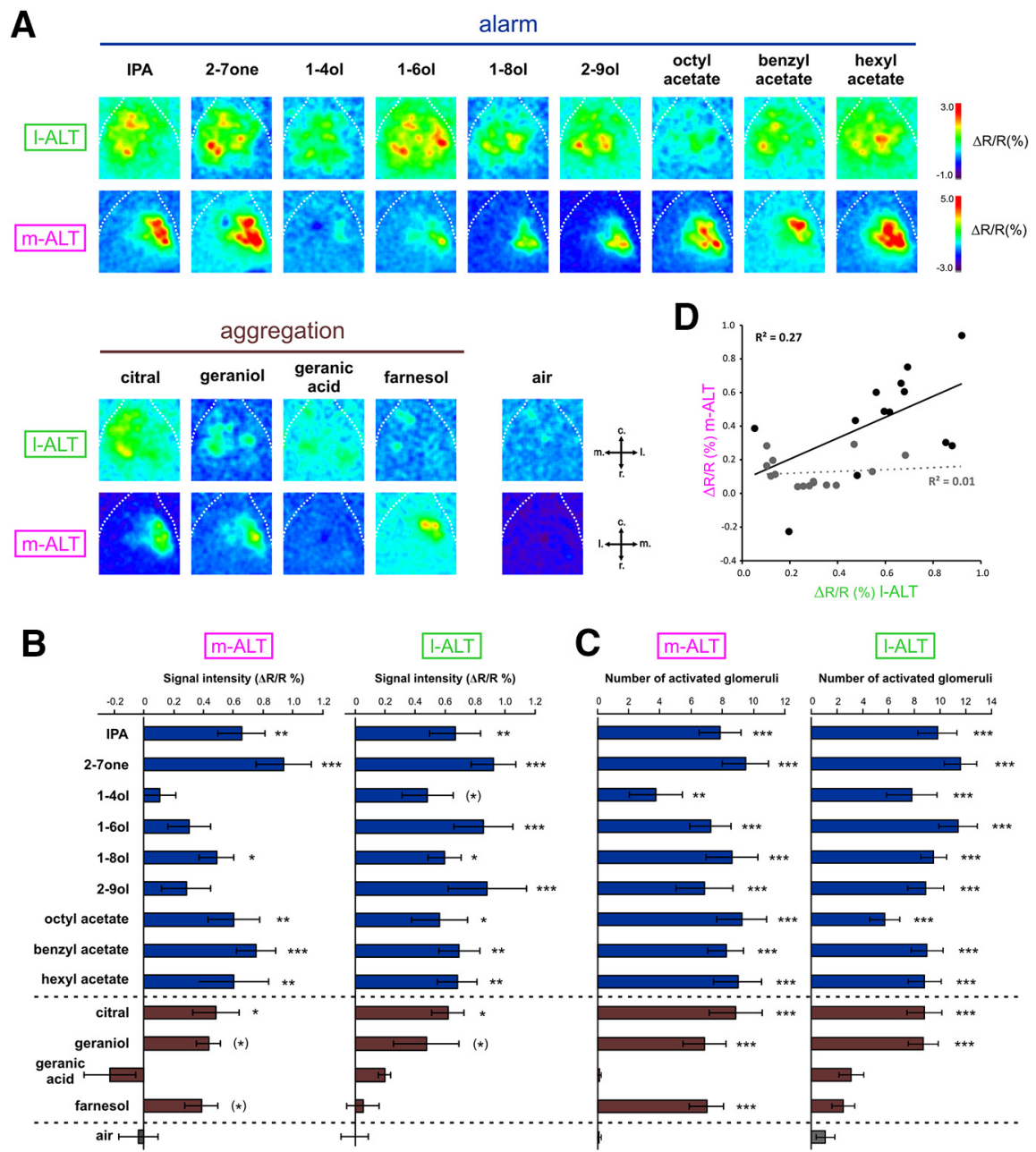

Figure 5. Responses to alarm and aggregation compounds in I-ALT and m-ALT PNs. A, Odor-induced calcium activity maps obtained from I-ALT (top) and m-ALT neurons (bottom) in different animals to 9 alarm compounds (in blue), 4 aggregation compounds (in brown), and to the control (air). Relative fluorescence changes $(\Delta R / R \%)$ are presented in a false-color code, from dark blue to red. $\boldsymbol{B}$, Amplitude of calcium responses ( $\Delta R / R \%)$. C, Numbers of activated glomeruli recorded for l-ALT $(n=10)$ and in $\mathrm{m}$-ALT neurons $(n=8)$ to alarm (in blue) and aggregation compounds (in brown). Gray represents responses to the air control. Error bars indicate SEM. $D$, Correlation between the amplitudes of calcium responses $(\Delta R / R \%)$ recorded in the I-ALT and $m$-ALT neurons for alarm and aggregation compounds (black circles and solid line) and for queen mandibular, nonmandibular, and brood compounds (gray circles and dashed line). Dunnett's test: ${ }^{*} p<0.05 ;{ }^{* *} p<0.01 ;{ }^{* * *} p<0.001 ;\left({ }^{*}\right) p<0.1$.

vious studies (Krofczik et al., 2009; Brill et al., 2013), these data show that representations were more narrowly tuned in m-ALT neurons than in 1-ALT neurons (Mann-Whitney test, population sparseness: $Z=3.41, p<0.001$; lifetime sparseness: $Z=6.54 ; p<$ $0.001)$. These pheromones are thus encoded in the honey bee AL as combinations of activated glomeruli following similar principles as general odorants. Within such combinatorial responses, one may ask whether specific glomeruli process one particular pheromone component or pheromone type, as is the case of 9-ODA in the honey bee drone AL (Sandoz, 2006). To answer this question, we sorted the glomeruli activated by each odorant according to four classes (Fig. 4B): "unique" (this glomerulus is activated only by this compound), "same type" (it is only coactivated by compounds from the same pheromone), "other type" (it is only coactivated by compounds that do not belong to the same pheromone) and "mixed" (it is coactivated both by components from the same pheromone and by other odorants). The result of this analysis performed on all detected odorants within each PN type is shown in Figure 4C. In l-ALT recordings (Fig. 4C, left), $80 \%$ of the glomeruli responding to QMP and its constituents were "mixed" glomeruli as they were activated by other queen mandibular components but also by other odorants. The rest of the glomeruli were mostly classified as "other type" as they were coactivated by other odorant classes. For queen nonmandibular components, which were differentially represented in the l-ALT and m-ALT subsystems (Fig. 2), almost all activated glomeruli were either "mixed" or "other type" glomeruli. In the case of brood pheromone components, "mixed" glomeruli were dominant (between 70\% and $90 \%$ ). The number of "unique" or "same type" glomeruli was extremely low for all odorants, with $<6 \%$ and $4 \%$, respectively, in both subsystems. These results suggest that queen and brood pheromones are not processed within specific dedicated glomeruli but as combinations of many broadly tuned glomeruli.

\section{Redundant processing of alarm and aggregation pheromones}

We then studied activity evoked by 9 alarm and 4 aggregation pheromone components produced by workers (Fig. 5A). We found that almost all the components of these two pheromones induced significant activity in both subsystems of the AL, as measured in terms of global response intensity (Fig. 5B; Dunnett's post hoc tests, $p<0.05$ ) or of number of activated glomeruli (Fig. 5C; Dunnett's post hoc tests, $p<$ $0.01)$. Only subtle differences were detectable between 1-ALT and m-ALT neurons, so that the correlation of odor-evoked response intensities or of activated glomeruli in both subsystems was on the verge of significance (response intensity, Fig. $5 D$, black circles, $R^{2}=0.27, p=0.069$; activated glomeruli, data not shown, $R^{2}=$ $0.29, p=0.057)$. By comparison, the same correlation analyses performed on queen and brood pheromones yielded $R^{2}$ values close to 0 and far from statistical significance (response intensity, Fig. $5 D$, gray circles, $R^{2}=0.01$, not significant; activated glomeruli, data not shown, $R^{2}=0.004$, not significant). Thus, the coding of alarm- and aggregation-pheromone components by both subsystems is mostly redundant.

We next assessed the qualitative coding of alarm and aggregation pheromone components in both subsystems. Pixelwise Euclidian distances were calculated among all possible stimulus pairs $(n=91)$, averaged over all individuals within each neuron class and used in multidimensional analyses. Cluster analyses (Fig. 6A, Ward's classification) showed several groupings of substances in the two subsystems, with a clear separation between components for which a response could be recorded (white boxes) and components for which no response was recorded (gray boxes). In 1-ALT neurons (Fig. 6A, left), no clear segregation based on pheromone identity was found. In m-ALT neurons (Fig. 6A, right), aggregation pheromone components clustered together with some alcohol alarm components. All acetate esters grouped together with the alarm component 2-heptanone. Prox- 
imity analyses (Fig. 6B) also demonstrated the existence of different groupings of pheromone components in the two subsystems, thus confirming cluster analyses with odorants being organized more strongly according to their chemical identity than according to their pheromonal message.

As in the first experiment, we used the glomerular data to evaluate population and lifetime sparseness for alarm and aggregation pheromones (Fig. 7B). We found a rather broad tuning of pheromone representation, with median values of 0.55 (l-ALT) and 0.63 (m-ALT) for population sparseness, and 0.46 (l-ALT) and 0.48 (m-ALT) for lifetime sparseness. Population sparseness was significantly higher in m-ALT neurons than in 1-ALT neurons (Mann-Whitney test, $Z=2.79$, $p<0.01)$, whereas lifetime sparseness did not differ between subsystems $(Z=0.73$, not significant). Last, we asked whether, within this combinatorial coding, specific glomeruli may be involved in the processing of aggregation or alarm pheromones. We thus sorted the glomeruli activated by each odorant according to four classes (see principle in Fig. 4B). As for queen and brood pheromones, we found a majority of mixed glomeruli (>70\%), suggesting that most glomeruli were activated both by other components of the same pheromone and by components of the other pheromone. For all components, $<5 \%$ of the glomeruli were classified as glomeruli uniquely activated by this odorant. Overall, these results show that alarm and aggregation components are also not processed within specific dedicated glomeruli, but as combinations of many broadly tuned glomeruli.

\section{Discussion}

We show that queen and brood pheromones are differentially processed by the two neural pathways of the bee brain: whereas queen mandibular components activate l-ALT neurons, brood pheromone components activate mostly m-ALT neurons. By contrast, components of the worker-emitted alarm and aggregation pheromones induce redundant activity in both subsystems. In addition, all tested pheromone components induce combinatorial activity from many glomeruli, which do not respond specifically to a given component but are rather activated by a wide range of odorant.

\section{Differential coding of pheromones in the two subsystems}

The two olfactory subsystems of the honey bee have been proposed to act as segregated information streams or as parallel processing systems (Galizia and Rössler, 2010; Rössler and Brill, 2013). The "dual segregated" hypothesis proposed that each subsystem processes information from different odorant types, whereas the "dual parallel" hypothesis proposed that both subsystems process information from the same odorants, but extract different odorant properties. Previous studies found essentially similar odor-response spectra in both systems, but identified differences in their response properties, processing rules or chemi- cal coding features (Abel et al., 2001; Müller et al., 2002; Krofczik et al., 2009; Yamagata et al., 2009; Carcaud et al., 2012; Galizia et al., 2012; Brill et al., 2013). These results supported, therefore, the "dual parallel" model, which was in consequence broadly accepted. By broadening the range of biologically relevant stimuli tested in both subsystems, our study shows differential activation of 1- ALT and m-ALT neurons in response to brood and queen pheromones, supporting a "dual segregated" model. In our view, this result is not in contradiction with previous studies but rather suggests that a more realistic model of bees' dual olfactory pathway should combine both theoretical strategies: although highly redundant in their odor-response spectra, the two subsystems contain specific sensitivities for particular odorant types (e.g., brood vs queen pheromone). In addition, both subsystems also support different processing principles, which may be particularly adapted to the odorants processed by each subsystem.

Neuroanatomical and genetic data also promote the idea of partly segregated coding in both subsystems. At the peripheral level, ORNs expressing the same odorant receptor (OR) usually project to a single glomerulus (Vosshall et al., 2000). The bee genome contains 163 potentially functional ORs, which compared with the $\sim 165$ AL glomeruli, supports a one-receptor type/ one-glomerulus organization (Robertson and Wanner, 2006). l-ALT and m-ALT PNs are uniglomerular neurons and thus gather information from two nonoverlapping OR sets (Sandoz, 2011). Therefore, it seems unlikely that the odor-response spectra of both subsystems are strictly similar. Possibly, the two OR sets corresponding to l-ALT and m-ALT subsystems correspond to phylogenetically different subgroups in the honey bee genome. 
A
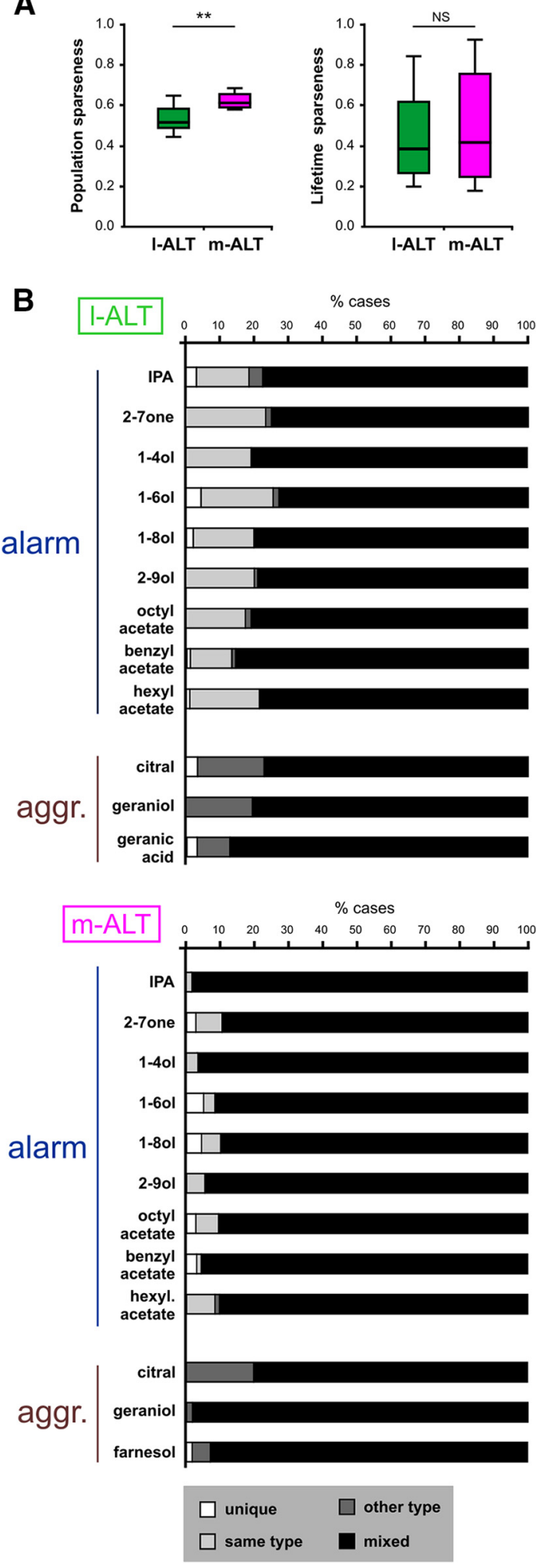

Figure 7. Representation sparseness and glomerular coactivation for alarm and aggregation pheromone. $A$, Population sparseness and lifetime sparseness measured from I-ALT and m-ALT recordings to alarm and aggregation pheromone compounds. Boxes represent the median and first and third quartiles. Whiskers represent $10 \%$ and $90 \%$ percentiles. ${ }^{* *} p<0.01$. $B$, Glomerular coactivation. Representation for each compound, of the percentage of glomeruli observed in the four classes (for definitions, see Fig. 4B): white represents unique; light gray represents same type; dark gray represents other type; black represents mixed. Only compounds that induced significant activity in I-ALT (top) or m-ALT neurons (bottom) are represented. The majority of glomeruli are mixed glomeruli, being activated both by other compounds of the same pheromone and by other odorants.
Cladiograms of honey bee ORs (Robertson and Wanner, 2006; their Fig. 1) suggest that, among the 157 ORs belonging to the honey bee-specific expansion, a major separation gives rise to two main subgroups of $\sim 75$ ORs. We speculate that some ORs corresponding to l-ALT glomeruli would be sensitive to decenoic acids and aromatic molecules (composing the QMP), whereas some ORs corresponding to m-ALT glomeruli would be sensitive to long-chain esters (brood pheromone components). However, many ORs from both subsystems should respond to components of worker-emitted alarm and aggregation pheromones, as well as to most floral odorants tested until now, which are simple aliphatic molecules (alcohols, ketones, short chain esters, etc.). Testing these hypotheses will require mapping all known ORs to each subsystem, as well as measuring their odor responses, for instance after expression in heterologous systems, such as Xenopus ovocytes (Wanner et al., 2007) or Spodoptera Sf9 cells (Claudianos et al., 2014).

\section{Pheromone processing within the $\mathrm{AL}$}

Historically, olfactory processing was proposed to follow one of two main models (Sandoz et al., 2007; Galizia and Rössler, 2010; Martin et al., 2011; Galizia, 2014): the labeled-line or the combinatorial model. The labeled-line model posits that a highly specific OR set detects one or very few stimuli, and information about this molecule is transmitted to a single glomerulus. Then, projection neurons innervating this glomerulus relay information about this stimulus to higher-order centers in this single channel (Christensen and Hildebrand, 1987; Datta et al., 2008; Ai et al., 2010; Stensmyr et al., 2012). Alternatively, the combinatorial model posits that each OR is less specific and can bind a much higher number of molecules. Each odorant activates many ORs, and consequently many glomeruli, with different intensities. Higher-order centers need to extract information from many channels at the same time to determine specific odorant information. This system is much more common and applies to general odor coding in insects (Sachse et al., 1999; Sadek et al., 2002; Wilson et al., 2004; Knaden et al., 2012; Brill et al., 2013). All pheromone components tested here, regardless of their origin (queen, brood, or workers), followed a combinatorial coding model. However, because our technique does not give access to all glomeruli within both subsystems, highly specific glomeruli may still be hidden in parts of the AL that were not accessible. For instance, the queen pheromone 9-ODA is processed by a labeledline system in male bees (drones). Their AL contains four enlarged macroglomeruli, one of which (MG2) responds exclusively to 9-ODA (Sandoz, 2006). AmOR11, the OR detecting 9-ODA, is strongly expressed in drones' antennae but is also expressed in workers', although at 10-25 times lower levels (Wanner et al., 2007). It is thus possible that, within the worker AL, one glomerulus is specific for 9-ODA. In any case, our data show that it would not be the only glomerulus responding to this pheromone.

\section{Pheromone processing in higher-order brain centers}

If combinatorial coding of pheromonal compounds is the rule in the worker AL, then higher-order brain areas are necessary for decoding PN activity patterns and assigning a pheromonal value to these odorants. As l-ALT and m-ALT PNs project to the MBs and the LH, both structures might play such role. The LH is considered as a premotor center mediating fast and innate reactions to biologically relevant stimuli. In Drosophila, the processing of pheromones in the LH seems to be segregated from that of food-related odorants (Jefferis et al., 2007). In male moths and 
ant workers, pheromone-responsive PNs innervate partially segregated regions of the LH compared with other PNs (Kanzaki et al., 2003; Seki et al., 2005). These data could suggest the possible existence of pheromone-specific neurons in the bee LH, serving premotor functions for releasing innate responses to pheromones. In honeybees, imaging of $\mathrm{PN}$ processes in the $\mathrm{LH}$ did not show any pheromone-specific regions, but through combinatorial readout, segregation of the main pheromone types would be possible (Roussel et al., 2014).

1-ALT and m-ALT PNs also project to the MBs, where they synapse with MB-intrinsic neurons, the Kenyon cells (KCs). KCs are highly odor specific and are activated by the combinatorial input from many different PNs (Szyszka et al., 2005). Therefore, KCs could decode specific combinatorial patterns at the PN level and thus encode pheromonal identity (Sandoz et al., 2007). Information from the KCs is then read out by MB-extrinsic neurons, which project to different parts of the protocerebrum or feed back into the MB calyces. It would thus be important to compare the responses of both $\mathrm{KCs}$ and $\mathrm{MB}$-extrinsic neurons to pheromonal and general odorants to find potential pheromonespecific neural units (Okada et al., 2007; Strube-Bloss et al., 2011).

\section{Advantages/limitations of the present approach}

Thanks to specific retrograde staining of m-ALT neurons coupled to a ventral preparation (Carcaud et al., 2012), we performed the first comparative imaging study of the responses of m-ALT and l-ALT neurons in the AL. Optical imaging offers the advantage of accessing many functional units simultaneously. This allowed recording combinatorial activity reliably within each subsystem and measuring odor-similarity relationships with precision. However, this approach still presents some limitations. First, because of the either ventral or dorsal access to the antennal lobe, only one subsystem can be accessed within each animal. Second, our technique necessitates direct optical access to the recorded units, so that we can measure from $\sim 34.6 \pm 2.1$ l-ALT glomeruli $(\sim 41 \%)$ and $\sim 36.8 \pm 1.6 \mathrm{~m}$-ALT glomeruli $(\sim 48 \%)$ (Carcaud et al., 2012). Therefore, approximately half of the glomeruli within each system remain hidden to us. Here, electrophysiological techniques can help (Müller et al., 2002; Krofczik et al., 2009), as they access fewer units simultaneously but can record from neurons that were not measured here. A recent multiunit approach even allows accessing both systems simultaneously within one animal (Brill et al., 2013). Both techniques are thus complementary for unraveling the roles of l-ALT and m-ALT pathways. In our case, coupling our staining and preparation techniques with other approaches, such as gold mirrors (Galizia et al., 2012) or two-photon microscopy (Brandstaetter and Kleineidam, 2011), may help overcome the above-mentioned limitations and access an extensive portion of both subsystems simultaneously.

In conclusion, we show that honeybee pheromone components induce combinatorial activity at the PN level, which is partly segregated in 1-ALT and m-ALT subsystems. As individual PNs do not contain the necessary pheromonal information for triggering the respective behaviors, our search for the neural basis of pheromonal coding should move on to the higher-order centers, the LH and MBs.

\section{References}

Abel R, Rybak J, Menzel R (2001) Structure and response patterns of olfactory interneurons in the honeybee, Apis mellifera. J Comp Neurol 437: 363-383. CrossRef Medline
Ai M, Min S, Grosjean Y, Leblanc C, Bell R, Benton R, Suh GS (2010) Acid sensing by the Drosophila olfactory system. Nature 468:691-695. CrossRef Medline

Bhandawat V, Olsen SR, Gouwens NW, Schlief ML, Wilson RI (2007) Sensory processing in the Drosophila antennal lobe increases reliability and separability of ensemble odor representations. Nat Neurosci 10:14741482. CrossRef Medline

Boch R, Shearer DA, Stone BC (1962) Identification of isoamyl acetate as an active component in the sting pheromone of the honey bee. Nature 195: 1018-1020. CrossRef Medline

Brandstaetter AS, Kleineidam CJ (2011) Distributed representation of social odors indicates parallel processing in the antennal lobe of ants. J Neurophysiol 106:2437-2449. CrossRef Medline

Brill MF, Rosenbaum T, Reus I, Kleineidam CJ, Nawrot MP, Rössler W (2013) Parallel processing via a dual olfactory pathway in the honeybee. J Neurosci 33:2443-2456. CrossRef Medline

Carcaud J, Hill T, Giurfa M, Sandoz JC (2012) Differential coding by two olfactory subsystems in the honey bee brain. J Neurophysiol 108:11061121. CrossRef Medline

Christensen TA, Hildebrand JG (1987) Male-specific, sex pheromoneselective projection neurons in the antennal lobes of the moth Manduca sexta. J Comp Physiol A 160:553-569. CrossRef Medline

Christensen TA, Hildebrand JG (2002) Pheromonal and host-odor processing in the insect antennal lobe: how different? Curr Opin Neurobiol 12: 393-399. CrossRef Medline

Christensen TA, White J (2000) Representation of olfactory information in the brain. In: The neurobiology of taste and smell (Finger TE, Restrepo D, eds), pp 201-232. New York: Wiley.

Claudianos C, Lim J, Young M, Yan S, Cristino AS, Newcomb RD, Gunasekaran N, Reinhard J (2014) Odor memories regulate olfactory receptor expression in the sensory periphery. Eur J Neurosci 39:1642-1654. CrossRef Medline

Datta SR, Vasconcelos ML, Ruta V, Luo S, Wong A, Demir E, Flores J, Balonze K, Dickson BJ, Axel R (2008) The Drosophila pheromone cVA activates a sexually dimorphic neural circuit. Nature 452:473-477. CrossRef Medline

Deisig N, Giurfa M, Sandoz JC (2010) Antennal lobe processing increases separability of odor mixture representations in the honeybee. J Neurophysiol 103:2185-2194. CrossRef Medline

Dupuy F, Josens R, Giurfa M, Sandoz JC (2010) Calcium imaging in the ant Camponotus fellah reveals a conserved odour-similarity space in insects and mammals. BMC Neurosci 11:28. CrossRef Medline

Free JB (1987) Pheromones of social bees. London: Chapman and Hall.

Galizia CG (2014) Olfactory coding in the insect brain: data and conjectures. Eur J Neurosci 39:1784-1795. CrossRef Medline

Galizia CG, Menzel R (2001) The role of glomeruli in the neural representation of odours: results from optical recording studies. J Insect Physiol 47:115-130. CrossRef Medline

Galizia CG, Rössler W (2010) Parallel olfactory systems in insects: anatomy and function. Annu Rev Entomol 55:399-420. CrossRef Medline

Galizia CG, Vetter RS (2004) Optical methods for analyzing odor-evoked activity in the insect brain. In: Methods in insect sensory neuroscience (Christensen TA, ed), pp 345-392. Boca Raton, FL: CRC.

Galizia CG, Sachse S, Rappert A, Menzel R (1999) The glomerular code for odor representation is species specific in the honeybee Apis mellifera. Nat Neurosci 2:473-478. CrossRef Medline

Galizia CG, Franke T, Menzel R, Sandoz JC (2012) Optical imaging of concealed brain activity using a gold mirror in honeybees. J Insect Physiol 58:743-749. CrossRef Medline

Giurfa M, Núñez JA (1992) Honeybees mark with scent and reject recently visited flowers. Oecologia 89:113-117. CrossRef

Hourcade B, Perisse E, Devaud JM, Sandoz JC (2009) Long-term memory shapes the primary olfactory center of an insect brain. Learn Mem 16:607615. CrossRef Medline

Jefferis GS, Potter CJ, Chan AM, Marin EC, Rohlfing T, Maurer CR Jr, Luo L (2007) Comprehensive maps of Drosophila higher olfactory centers: spatially segregated fruit and pheromone representation. Cell 128:11871203. CrossRef Medline

Joerges J, Küttner A, Galizia CG, Menzel R (1997) Representations of odours and odour mixtures visualized in the honeybee brain. Nature 387:285-288. CrossRef

Kanzaki R, Soo K, Seki Y, Wada S (2003) Projections to higher olfactory 
centers from subdivisions of the antennal lobe macroglomerular complex of the male silkmoth. Chem Senses 28:113-130. CrossRef Medline

Keeling CI, Slessor KN, Higo HA, Winston ML (2003) New components of the honey bee (Apis mellifera L.) queen retinue pheromone. Proc Natl Acad Sci U S A 100:4486-4491. CrossRef Medline

Kirschner S, Kleineidam CJ, Zube C, Rybak J, Grünewald B, Rössler W (2006) Dual olfactory pathway in the honeybee, Apis mellifera. J Comp Neurol 499:933-952. CrossRef Medline

Knaden M, Strutz A, Ahsan J, Sachse S, Hansson BS (2012) Spatial representation of odorant valence in an insect brain. Cell Rep 1:392-399. CrossRef Medline

Krofczik S, Menzel R, Nawrot MP (2009) Rapid odor processing in the honeybee antennal lobe network. Front Comput Neurosci 2:9. CrossRef Medline

Kurtovic A, Widmer A, Dickson BJ (2007) A single class of olfactory neurons mediates behavioural responses to a Drosophila sex pheromone. Nature 446:542-546. CrossRef Medline

Le Conte Y, Arnold G, Trouiller J, Masson C (1990) Identification of a brood pheromone in honeybees. Naturwissenschaften 77:334-336. CrossRef

Le Conte Y, Mohammedi A, Robinson GE (2001) Primer effects of a brood pheromone on honeybee behavioural development. Proc Biol Sci 268: 163-168. CrossRef Medline

Martin JP, Beyerlein A, Dacks AM, Reisenman CE, Riffell JA, Lei H, Hildebrand JG (2011) The neurobiology of insect olfaction: sensory processing in a comparative context. Prog Neurobiol 95:427-447. CrossRef Medline

Mota T, Yamagata N, Giurfa M, Gronenberg W, Sandoz JC (2011) Neural organization and visual processing in the anterior optic tubercle of the honeybee brain. J Neurosci 31:11443-11456. CrossRef Medline

Müller D, Abel R, Brandt R, Zockler M, Menzel R (2002) Differential parallel processing of olfactory information in the honeybee, Apis mellifera $\mathrm{L}$. J Comp Physiol A 188:359-370. CrossRef Medline

Nawrot MP (2012) Dynamics of sensory processing in the dual olfactory pathway of the honeybee. Apidologie 43:269-291. CrossRef

Okada R, Rybak J, Manz G, Menzel R (2007) Learning-related plasticity in PE1 and other mushroom body-extrinsic neurons in the honeybee brain. J Neurosci 27:11736-11747. CrossRef Medline

Perez-Orive J, Mazor O, Turner GC, Cassenaer S, Wilson RI, Laurent G (2002) Oscillations and sparsening of odor representations in the mushroom body. Science 297:359-365. CrossRef Medline

Pickett JA, Williams IH, Martin AP, Smith MC (1980) Nasonov pheromone of the honeybee, Apis mellifera L. (Hymenoptera: Apidae): 1. Chemical characterization. J Chem Ecol 6 425-434.

Robertson HM, Wanner KW (2006) The chemoreceptor superfamily in the honey bee, Apis mellifera: expansion of the odorant, but not gustatory, receptor family. Genome Res 16:1395-1403. CrossRef Medline

Rössler W, Brill MF (2013) Parallel processing in the honeybee olfactory pathway: structure, function, and evolution. J Comp Physiol A 199:981996. CrossRef Medline

Roussel E, Carcaud J, Combe M, Giurfa M, Sandoz JC (2014) Olfactory coding in the honeybee lateral horn. Curr Biol 24:561-567. CrossRef Medline

Sachse S, Galizia CG (2002) Role of inhibition for temporal and spatial odor representation in olfactory output neurons: a calcium imaging study. J Neurophysiol 87:1106-1117. Medline

Sachse S, Rappert A, Galizia CG (1999) The spatial representation of chemical structures in the antennal lobe of honeybees: steps towards the olfactory code. Eur J Neurosci 11:3970-3982. CrossRef Medline

Sadek MM, Hansson BS, Rospars JP, Anton S (2002) Glomerular representation of plant volatiles and sex pheromone components in the antennal lobe of the female Spodoptera littoralis. J Exp Biol 205:1363-1376. Medline
Sandoz JC (2006) Odour-evoked responses to queen pheromone components and to plant odours using optical imaging in the antennal lobe of the honey bee drone Apis mellifera L. J Exp Biol 209:3587-3598. CrossRef Medline

Sandoz JC (2011) Behavioral and neurophysiological study of olfactory perception and learning in honeybees. Front Syst Neurosci 5:98. CrossRef Medline

Sandoz JC, Deisig N, de Brito Sanchez MG, Giurfa M (2007) Understanding the logics of pheromone processing in the honeybee brain: from labeledlines to across-fiber patterns. Front Behav Neurosci 1:5. CrossRef Medline

Seki Y, Aonuma H, Kanzaki R (2005) Pheromone processing center in the protocerebrum of Bombyx mori revealed by nitric oxide-induced anticGMP immunocytochemistry. J Comp Neurol 481:340-351. CrossRef Medline

Shearer DA, Boch R (1965) 2-Heptanone in the mandibular gland secretion of the honey bee. Nature $206530-530$.

Slessor KN, Kaminski LA, King GG, Borden JH, Winston ML (1988） Semiochemical basis of the retinue response to queen honey bees. Nature 332: 354-356. CrossRef

Slessor KN, Winston ML, Le Conte Y (2005) Pheromone communication in the honeybee (Apis mellifera L.). J Chem Ecol 31:2731-2745. CrossRef Medline

Stensmyr MC, Dweck HK, Farhan A, Ibba I, Strutz A, Mukunda L, Linz J, Grabe V, Steck K, Lavista-Llanos S, Wicher D, Sachse S, Knaden M, Becher PG, Seki Y, Hansson BS (2012) A conserved dedicated olfactory circuit for detecting harmful microbes in Drosophila. Cell 151:1345-1357. CrossRef Medline

Strube-Bloss MF, Nawrot MP, Menzel R (2011) Mushroom body output neurons encode odor-reward associations. J Neurosci 31:3129-3140. CrossRef Medline

Szyszka P, Ditzen M, Galkin A, Galizia CG, Menzel R (2005) Sparsening and temporal sharpening of olfactory representations in the honeybee mushroom bodies. J Neurophysiol 94:3303-3313. CrossRef Medline

Vickers NJ, Christensen TA, Baker TC, Hildebrand JG (2001) Odour-plume dynamics influence the brain's olfactory code. Nature 410:466-470. CrossRef Medline

Vosshall LB, Wong AM, Axel R (2000) An olfactory sensory map in the fly brain. Cell 102:147-159. CrossRef Medline

Wang S, Sato K, Giurfa M, Zhang S (2008) Processing of sting pheromone and its components in the antennal lobe of the worker honeybee. J Insect Physiol 54:833-841. CrossRef Medline

Wanner KW, Nichols AS, Walden KK, Brockmann A, Luetje CW, Robertson HM (2007) A honey bee odorant receptor for the queen substance 9-oxo-2-decenoic acid. Proc Natl Acad Sci U S A 104:14383-14388. CrossRef Medline

Willmore BD, Mazer JA, Gallant JL (2011) Sparse coding in striate and extrastriate visual cortex. J Neurophysiol 105:2907-2919. CrossRef Medline

Wilson RI, Turner GC, Laurent G (2004) Transformation of olfactory representations in the Drosophila antennal lobe. Science 303:366-370. CrossRef Medline

Winston ML (1987) The biology of the honey bee. Cambridge, MA: Harvard UP.

Wyatt TD (2003) Pheromones and animal behaviour: communication by smell and taste. Cambridge UP.

Yamagata N, Schmuker M, Szyszka P, Mizunami M, Menzel R (2009) Differential odor processing in two olfactory pathways in the honeybee. Front Syst Neurosci 3:16. CrossRef Medline

Zube C, Kleineidam CJ, Kirschner S, Neef J, Rössler W (2008) Organization of the olfactory pathway and odor processing in the antennal lobe of the ant Camponotus floridanus. J Comp Neurol 506:425-441. CrossRef Medline 